\title{
TEORIA DE JÜRGEN HABERMAS APLICADA NA ANÁLISE DO DIREITO
}

\section{JÜRGEN HABERMA'S THEORY APPLIED IN THE ANALYSIS OF LAW}

\begin{abstract}
Irineu Francisco Barreto Junior
Pós-doutor em Sociologia pela Universidade de São Paulo. Doutor em Ciências Sociais pela PUC-SP. Docente do Programa de Mestrado em Direito da Sociedade da Informação e do curso de graduação em Direito do Centro Universitário das Faculdades Metropolitanas Unidas (FMU-SP). Coordenador do grupo de pesquisa CAPES Ética e Fundamentos JurídicoPolíticos na Sociedade da Informação. Analista de pesquisas da Fundação Seade. irineu.jr@fmu.br

Nivaldo Sebastião Vicola

Doutorando em Direito pela Universidade de São Paulo. Mestre em Direito pela Universidade de São Paulo. Bacharel em Direito pelo Centro Universitário das Faculdades Metropolitanas Unidas (FMU-SP). nivaldo.vicola@fmu.br

\section{Ernesto Lyoma Kurauchi}

Internacionalista e advogado. Pesquisador do grupo de pesquisa CAPES Ética e Fundamentos Jurídico-Políticos da Sociedade da Informação. Bacharel em Direito pelo Centro Universitário das Faculdades Metropolitanas Unidas (FMU-SP). ryo_kurauchi@hotmail.com
\end{abstract}

RESUMO: Este artigo atualiza conceitos centrais de Jürgen Habermas, pensador da corrente teórica denominada Escola de Frankfurt, com o intuito de analisar sua aplicabilidade e alcance para a análise do Direito e da sociedade brasileira contemporânea. Para atingir esse objetivo, realiza uma revisão das teorias da ação comunicativa e da ética discursiva, elementos centrais da concepção habermasiana, que perpassam a Filosofia, a Sociologia e a Ciência Jurídica. O artigo considera essas três perspectivas indissolúveis e as contempla ao analisar atributos atuais do direito e da sociedade, a saber, formulação e vitalidade da democracia, esfera pública e validade da norma jurídica. Cabe ressaltar que a escola habermasiana é notoriamente conhecida pela sua complexidade, na medida que integra diferentes segmentos de pensamentos e teorias. Conclui que é pelo exercício da racionalidade que será possível construir conhecimento confiável e normas morais universais. O Direito como instrumento de mediação social, necessita ser legitimado e validado por vias discursivas, pautado nas racionalidades éticas e morais, princípios renovados pela ideologia da modernidade na perspectiva de Habermas.

PALAVRAS-CHAVE: Escola de Frankfurt; Jürgen Habermas; Sociologia do Direito; Filosofia do Direito.

ABSTRACT: This article updates the central concepts of Jürgen Habermas, theoretical current thinker called Frankfurt School, in order to analyze aspects of law and contemporary Brazilian society. To this end it carries out a review of the theories of communicative action and discourse ethics, important elements of Habermas's conception, 
which pervade the Philosophy, Sociology and Legal Science. The article considers these three indissoluble perspectives and includes when analyzing aspects of the law and social life: development and vitality of democracy, public sphere and validity of the legal norm. It notes that Habermas's school is well known for its complexity, as it integrates different segments of thoughts and theories. It concludes that it is through the exercise of rationality that will be possible to build reliable knowledge and universal moral norms. The law as social mediation instrument needs to be legitimized and validated by discursive way, based on ethical and moral rationales, principles renewed by the Habermas modernity ideology.

KEYWORDS: Frankfurt School; Jürgen Habermas; Sociology of Law; Philosophy of law.

\section{INTRODUÇÃO}

Representante da abordagem teórica conhecida como segunda geração da Escola de Frankfurt - corrente de pensamento formulada por intelectuais como Walter Benjamin, Max Horkheimer, Theodor Adorno e Herbert Marcuse - Jürgen Habermas é um pensador interdisciplinar, cujos trabalhos transcendem as rígidas fronteiras entre as disciplinas acadêmicas. Com suas reflexões sobre questões urgentes da contemporaneidade, que transitam por diversas áreas do conhecimento sem perder a percepção do conjunto própria do saber filosófico, é um dos mais importantes e influentes pensadores da atualidade. Cabe ressaltar que a escola Habermasiana é notoriamente conhecida pela sua complexidade, na medida em que integra diferentes segmentos de pensamentos e teorias. O presente estudo apresenta como objetivos abordar a teoria social e discursiva, desenvolvida por Habermas e a Escola de Frankfurt, e analisar seu percurso conceitual em direção ao agir comunicativo, dirigido à formação do indivíduo como membro de grupo social específico e cidadão de uma comunidade política maior.

Pelo padrão de erudição e complexidade da escola de Frankfurt seria ambicioso abordar, em uma única publicação, todo grau de complexidade e expansividade que propõem esta escola. Assim, as unidades lógicas do artigo seguirão uma estrutura sistêmica, consubstanciada na interpretação da dinâmica política entre as classes e grupos sociais, relacionando-os com a teoria de Frankfurt e o pensamento de Habermas: o direito como instrumento de mediação social, facticidade e validade, modernidade, o papel da Filosofia e da Sociologia, esfera pública, democracia radical e suas aplicabilidades na validação de uma norma jurídica.

\section{O DIREITO COMO INSTRUMENTO DE MEDIAÇÃO SOCIAL}

\subsection{DIREITO COMO MATÉRIA DE FORÇA INTEGRADORA}

Teorias sociológicas, teorias do direito, teorias linguísticas, teorias do Estado, sociologia política, sociologia da comunicação, dialética do público e do privado, questões da formação da opinião pública, da soberania do povo, o direito das minorias, a ação da sociedade civil, 
poder das massas, jurisprudência e jurisdição. $\mathrm{O}$ amálgama que permite interpretar todos esses fragmentos, aparentes e reais, para a construção de uma teoria discursiva do direito, é originário das categorias oriundas da Sociologia e da Filosofia. Estas duas correntes teóricas são forças integradoras que reificam o mundo vivido e possibilitam miradas sobre os sistemas jurídico, político e econômico (FREITAG, 2005, p. 193). O direito, por sua vez, atua nesta sistemática como função operacional, regulamentando a economia e o poder, instrumentalizando-se para ordenar o que os mecanismos de integração sistêmica já não conseguem mais regulamentar e controlar (motivação e disposição interna dos atores em contextos políticos sociais e cotidianos).

Assim como o direito atua nos subsistemas dos poderes (economia e política) nas modernas sociedades, principalmente, equilibra, ordena e integraliza os impulsos e expectativas dos atores. Desta forma, as expectativas de ação e interação entre os atores passam a ser formas internalizadas de sistemas normativos e legais, introduzidos por vias argumentativas, aos quais os atores aderem por convicção e convencimento (FREITAG, 2005, p. 184).

\subsection{FACTICIDADE E VALIDADE: A PROVA HABERMESIANA FRENTE À WEBERIANA}

O direito regula e redefine, histórica e normativamente, a relação entre facticidade e validade (fatos e normas), aproximando essas duas categorias fundamentais. Em sua obra Direito e Democracia, Habermas dedica a sua análise às questões constitucionais e ao trabalho dos tribunais; como forma de analisar a legitimidade e legalidade das normas. Possuindo como objeto de estudo as práticas de jurisdição norte-americanas comparando com as práticas do Estado de Direito alemão. Surgindo, assim, críticas inevitáveis a C. Schmitt, Savigny, Kelsen e, principalmente, a Max Weber (MCCARTHY, 1984, p. 173).

Primeiramente, Habermas problematiza Weber; para este a legitimidade de uma ordem social pode alimentar-se de várias fontes (principalmente: efetividade, tradição, uso e direito), buscando nestas o fornecimento do fundamento indispensável para a legalidade. Esta, por sua vez, depende da lei escrita e prescrita, bem como de instituições competentes para implementálas: quadros judiciários, administrativos, policiais e militares. Compreende-se, desta forma, que, em Weber, há uma sequência natural e lógica entre os antecedentes (legitimidade) e os consequentes (legalidade). Para Habermas, na formulação de McCarthy (1984, p. 173):

\footnotetext{
A ação comunicativa surge como uma interação de, no mínimo dois sujeitos, capazes de falar e agir, que estabelecem relações interpessoais com o objetivo de alcançar uma compreensão sobre a situação em que ocorre a interação e sobre os respectivos planos de ação com vistas a coordenar suas ações pela via do entendimento. Neste processo, eles se remetem a pretensões de validade criticáveis quanto à sua veracidade, correção normativa e autenticidade, cada uma destas pretensões referindo-se respectivamente a um mundo objetivo dos fatos, a um mundo social das normas e a um mundo das experiências subjetivas (grifo nosso). Para construção deste conceito, ele se baseou no interacionismo simbólico de Mead, no conceito de jogos de linguagem de Wittgenstein, na teoria dos atos de fala de Austin e na hermenêutica de Gadamer. (MCCARTHY, 1984, p. 173)
} 
Habermas (FREITAG, 2005, p. 195), por sua vez, propicia uma guinada analítica, uma espécie de normative turn, e argumenta que as ordens institucionais legais (legalidade), em sociedades modernas, são legítimas em sua ordem, desde que atendidos certos critérios democráticos e princípios discursivos. Em um Estado Democrático de Direito, a legitimidade depende da ordem social, e, para que seja efetivamente legítima, esta precisa ter elaborado as suas leis (constituição, legislação comum), as normas de sua aplicação (administração pública) e as formas de seu controle (judiciário), pelas vias argumentativas, que caracterizam os discursos teóricos, éticos e práticos (FREITAG, 2005, p. 208-210). Assim, a tensão entre facticidade e validade se acirra, porque Habermas não inverte simplesmente a relação entre legitimidade e legalidade (FREITAG, 2005, p. 208-210), postulada por Weber, mas, problematiza o entendimento weberiano a partir da facticidade de uma ordem social. Em suma, conclui-se que a facticidade e a validade referem-se a uma realidade social, oriunda simultaneamente de duas fontes (FREITAG, 2005, p. 208-210): (a) de processos históricos e sociais espontâneos, cuja normatividade pode ser atribuída ao sentimento comunitarista e à tradição; e (b) de práticas normativas, deduzidas da legislação vigente. Tais facticidade e validade somente teriam validade ética e jurídica, papel de força integradora social e legitimidade, se as normas e leis que a regem tivessem sido elaboradas discursivamente, conforme os critérios descritos.

\subsection{MODERNIDADE: AÇÃO COMUNICATIVA ORIENTADA PELA RACIONALIDADE COMUNICATIVA}

Habermas retorna ao diagnóstico weberiano e concorda no que concerne à modernização da economia e do Estado, como apoia a sua tese da racionalização e autonomização das diferentes esferas de valor. Contudo, observa que devem ser evitadas algumas simplificações, como cortar etapas e omitir diferenciações, a fim de diagnosticar corretamente a dinâmica e estrutura de uma sociedade moderna. No entendimento de Habermas; Weber ainda acerta, ao postular a racionalização e a autonomização das três esferas de valor, mas peca ao analisar somente a esfera ética. Além dessa redução da análise a uma única esfera cultural, Weber comete um segundo reducionismo, ao enfocar a esfera ética somente pelas formas de institucionalização do ethos do trabalho no interior do moderno sistema econômico. Desta forma, outros aspectos da racionalização e autonomização no interior da esfera ética são omitidos ou abandonados (FREITAG, 2005, p. 194). McCarthy (1984, p. 180-181) insere nas inferências de Habermas sobre Weber a formulação de dialética negativa de Adorno e Horkheimer:

Haverá, então, Habermas chegado aos mesmos dilemas da dialética negativa de Adorno e Horkheimer, ou àqueles da análise weberiana? Ou seja, será que o desenvolvimento da razão acaba gerando inexoravelmente os elementos que levam à destruição de lodo o seu potencial emancipatório e iluminista? Habermas acredita que não, porque, ao contrário destes autores, ele não confunde o desenvolvimento da razão instrumental como sendo o próprio processo de racionalização societária. Esta confusão levou Weber, Adorno e Horkheimer a buscar a espontaneidade livre da reificação em poderes irracionais (carisma, arte e amor). (MCCARTHY, 1984, p. 180-181) 
Contudo, o pensamento weberiano forneceu a Habermas o paradigma geral da modernização societária, identificando a racionalização com a modernização. Partindo da tese da racionalização do mundo a partir das concepções religiosas, tão brilhantemente analisada (entre outras) no exemplo da Ética Protestante e o Espírito do Capitalismo, Weber não parece ter dúvidas quanto à validade da equação: modernização equipara-se à racionalização. A modernidade ocorreu, segundo Weber, nessa forma típica ideal, isto é, quase caricatural; em processos isolados de racionalização (economia de mercado, contabilidade, burocratização, etc.) coexistindo simultaneamente e no mesmo lugar em suas manifestações mais puras e extremas. Longe de idealizar a modernidade, Weber lamenta certos traços desse período, já que a racionalização do mundo levou ao seu desencantamento, considerando esta importância universal inevitável e irreversível (FREITAG, 2005, p. 172).

Habermas, ao contrário, interpreta a modernidade como algo cultural, um processo de transformação em que se concretizou a ação comunicativa orientada pela racionalidade. A autonomização das esferas da cultura instaura o debate aberto, e não preconceituoso, das concepções de mundo no interior do subsistema cultural. A autorreflexão e crítica impõem à ciência, à moral e à arte fornecer novos modelos interpretativos do processo de transformação, baseados na razão comunicativa, liberada da coerção monológica de concepções pré-concebidas (FREITAG, 2005, p. 172).

Cabe ressaltar que, até aqui, Habermas problematizou a questão do Direito como instrumento de mediação e integrador social, na qual as leis e normas, somente seriam legítimas e válidas desde que formulados e observados por vias argumentativas e baseadas na racionalidade. Enquanto as normas podem e devem ser submetidas a um procedimento discursivo para adquirirem sua validade, os valores devem ser analisados no campo do mundo vivido e ao subsistema cultural, onde devem se desprender de conceitos pré-concebidos, para fins de uma validação universal. A modernidade por sua vez, não deve levar somente à modernidade no sentido stricto sensu, mas, a um processo de transformação ética e moral do indivíduo, orientada pela racionalidade.

\subsubsection{TEORIA DA AÇÃO COMUNICATIVA E DA ÉTICA DISCURSIVA}

Sistematiza-se desta forma, a tensão entre facticidade e validade no contexto da linguagem e da ação comunicativa. Os dois conceitos coexistem sem atrito, enquanto nos movimentamos no mundo vivido, ou seja, enquanto as relações sociais e comunicativas que caracterizam nossa vivência cotidiana não forem problematizadas (FREITAG, 2005, p. 59-63). As diferentes implicações sociológicas e políticas que um e outro conceito podem ter, somente vêm à tona, quando os atores põem em questão as pretensões de validade implícitas em qualquer ato do saber comunicativo, suspendendo as relações comunicativas habituais até então aceitas sem questionamentos, inaugura-se, então, uma nova forma comunicativa (FREITAG, 2005, p. 59-63). 
Para McCarthy (1984, p. 182):

Este paradigma não se sustenta mais. Depois que Hegel mostrou o caráter intrinsecamente social e histórico das estruturas da consciência, que Marx revelou que a mente não é o campo da natureza, mas o inverso e que as formas de consciência são representações ocultas das formas de reprodução social; depois que Darwin estabeleceu o vínculo entre inteligência e sobrevivência e, finalmente, que Nietzsche e Freud revelaram o inconsciente no âmago da consciência, dá-se uma dessublimação do espírito e um enfraquecimento da filosofia. (MCCARTHY, 1984, p. 182)

Em outras palavras: (1) os locutores convencem seus parceiros da veracidade de sua fala, fazendo-a coincidir com suas ações; (2) os argumentos verdadeiros passam a prevalecer, quando eles fundamentam, de forma convincente, as proposições feitas; e (3) as normas são reavaliadas e revalidadas, quando são compreendidas, respeitadas e aceitas por todos os integrantes de uma situação dialógica como sendo justas e boas (FREITAG, 2005, p. 191).

Em sua obra Faktizitat und Geltung, Habermas esclarece como a tensão entre os fatos sociais e sua validade normativa se desenvolve no campo do direito e do poder, incluindo-se suas formas de institucionalização na sociedade e no Estado de Direito. Na era do pensamento pós-metafísico, fatos históricos ou sociologicamente constituídos são constantemente repensados e reconstruídos normativamente com auxílio de constituições, legislações e julgamentos dos tribunais, que, deste modo, interferem na prática cotidiana. Ao lado da normatividade do legislativo e do judiciário, o poder executivo aplica (bem ou mal) as leis em vigor, estruturando a realidade social. A normatividade da lei, internalizada pelos atores, gera, desta forma, expectativas sociais, que se traduzem em ações sociais. Essas, longe de serem espontâneas ou resultantes de processos comunicativos autênticos, resultam da legalidade do poder racional instituído e não da ação comunicativa e ética discursiva, fugindo, desta forma, da ótica do mundo vivido e, consequentemente, da facticidade e validade.

\subsection{O PAPEL DA FILOSOFIA E DA SOCIOLOGIA}

A Filosofia e a Sociologia, desta forma, teriam papel fundamental como norteadores de formação da opinião pública, racionalizando os agentes envolvidos a criarem uma moral e ética comumente e em sintonia com as transformações sociais e da modernidade. Contudo, a Filosofia e a Sociologia possuem peculiaridades em algumas atribuições. A Filosofia possui seu papel como intérprete do mundo vivido, mantendo uma relação íntima com o senso comum, especialmente próximo daquilo que, intuitivamente, sabemos de antemão, mantendo, ao mesmo tempo, um olhar crítico e o chamado bom senso (PINTO, 1995, p. 81).

Examinando os modelos interpretativos da modernidade. Habermas ainda atribui aos filósofos duas tarefas centrais: em primeiro lugar, fornecerem modelos interpretativos (e críticos) da modernidade cultural, isto é, das transformações que ocorrem; em segundo lugar, cooperarem com outros ramos das ciências humanas, especialmente aqueles interessados em questões 
universalistas. Desse modo, poderão ser fortalecidas estratégias teóricas, que são ameaçadas pelo inducionismo e elementarismo; estratégias essas permitiriam aos sociólogos uma compreensão crítica, viabilizando uma correção da modernidade e de suas respectivas patologias, que afetam tanto o mundo vivido quanto o seu sistema (direito, política, mercado e estado) automatizados (HABERMAS, 1980, p. 488).

Outrossim, os sociólogos devem concentrar sua atenção no sistema e na modernidade societária, dialogando com os filósofos que, por sua vez, concentrariam sua atenção no mundo vivido e na modernidade cultural. Mas, para que as evidências fornecidas pela Sociologia alimentem a Filosofia, e vice-versa, é necessário que ocorra uma cooperação factível e intensa (FREITAG, 2005, p. 175). Contudo, as análises podem se tornar problemáticas quando os filósofos generalizam suas reflexões críticas (oriundas do mundo vivido) de forma indiferenciada para o sistema. Igualmente problemática é a operação inversa, quando fenômenos e transformações ocorridas no sistema são generalizadas acriticamente para diagnosticar o mundo vivido. Adorno seria um exemplo para o primeiro caso, Foucault para o segundo (FREITAG, 2005, p. 175).

A modernidade somente será compreendida, em toda a sua complexidade, potencialidades e patologias, fornecendo-se um modelo interpretativo que abranja os dois aspectos da modernidade (a modernidade moral e ética e a modernização sistêmica - "política e cultural"). As falsas interpretações não somente obstruem o caminho para uma compreensão correta, elas sustentam, muitas vezes involuntariamente, as estruturas que bloqueiam a solução e a superação das patologias modernas, impedindo a implementação de novos conceitos morais e éticos, obstruindo projetos autênticos e emancipatórios (HABERMAS, 1980, p. 488).

Por fim, Habermas concede e pontua algumas ideias no que cerne à problemática no discurso filosófico e sociológico da modernidade: Na medida em que pretendeu fornecer modelos ideológicos que substituíssem as concepções religiosas do mundo, o marxismo ortodoxo forneceu interpretações distorcidas, seja da modernização societária, seja da modernidade cultural.

\section{DIREITO E DEMOCRACIA: ENTRE FACTICIDADE E VALIDADE}

\subsection{A NECESSIDADE DE FORTALECER A DEMOCRACIA}

Como visto, foi abordado, até aqui, o papel do Direito como instrumento de mediação e integrador social; a sua legalidade e legitimidade por vias discursivas e da racionalidade, norteados pelas transformações sociais (modernidade). A modernidade, por sua vez, não deve levar somente à modernidade no sentido stricto sensu, mas, para um processo de transformação ético e moral do indivíduo, orientado pelos sociólogos e filósofos que teriam a função de intérpretes, racionalizando os valores dos agentes com as transformações do mundo vivido e do mundo sistêmico. Habermas, em sua teoria da ação comunicativa e em sua teoria discursiva do direito, é defensor de uma democracia radical, praticada em todos os níveis e nichos do 
mundo vivido e sistêmico. Nisso, Habermas se distancia de Adorno e Horkheimer, que viam na democracia atual um fenômeno de massa e uma ameaça à sobrevivência da razão. Em contrapartida aos seus antecessores, Habermas ainda aposta no poder do diálogo e na razão comunicativa que se estabelece entre os membros de uma situação discursiva em que prevalece o melhor argumento e a busca do entendimento mútuo.

\subsection{RADICALIDADE DEMOCRÁTICA (NORMAS E LEIS)}

A radicalidade democrática de Habermas leva os indivíduos a se defrontarem com normas e leis que até então recentemente não precisavam ser validadas em discursos teóricos e práticos, pois sua legitimidade era assegurada por outras fontes (Deus, natureza, autoridade do Estado, tradição, prática cotidiana). Uma vez introduzida a ideia do discurso que implica a suspensão da validade dessas fontes legitimadoras, a validade e legitimidade de uma norma ou lei dependem de processos argumentativos democráticos, livres de coação, em que todos podem e devem ter acesso aos processos comunicativos, desconstruindo, desta forma, a estrutura weberiana e ratificando o pensamento habermasiano de facticidade e validade (HABERMAS, 1980, p. 190). Somente depois de superadas as dúvidas e questionamentos, por parte de todos os interlocutores, é que a fala cotidiana se restabelece e a nova legitimidade pode ser implementada.

\subsection{ESFERA PÚBLICA}

$\mathrm{Na}$ visão habermasiana, a esfera pública se constitui como instância deliberativa e legitimadora do poder político. Seria, desta forma, um espaço de mediação entre o campo das relações privadas e o poder público; algo próximo do parlamentarismo (HABERMAS, 1980, p. 490). A proposta de Habermas, e ampliando o espectro de influência do seu conceito, qualquer tema de relevância pública, quer seja da burguesia, da classe operária ou de outros grupos, enfim, da coletividade, precisam ser submetidos à abordagem crítica. Uma vontade individual ou de grupos não pode ser imposta. Vontades individuais precisam ser transformadas em uma vontade geral, sendo construída racionalmente (HABERMAS, 1980, p. 190).

Em síntese, esfera ou espaço público é um fenômeno social elementar, pode ser descrito como uma rede adequada para a comunicação de conteúdos, tomadas de posições e opiniões; nela, os fluxos comunicacionais são filtrados e sintetizados, a ponto de se condensarem em opiniões públicas enfeixadas em temas específicos (HABERMAS, 1980, p. 190). A esfera pública também leva a um fortalecimento dos aspectos relacionados à intelectualidade, ao passo que a separação entre opiniões compartilhadas leva a uma indiferença da orientação leiga; e as obrigações concretas da ação caminham a um processo de formação de opinião. Outrossim, a esfera pública não pode ser representativa no sentido estatístico, não constitui um agregado de opiniões individuais pesquisadas uma a uma ou manifestadas privadamente; por isso, ela não pode ser confundida com meros resultados de pesquisa de opinião. Visto pelo lado normativo, a 
esfera pública fundamenta uma medida para a legitimidade da influência exercida por opiniões públicas sobre o sistema político. Cria-se, portanto, uma intersecção pessoal entre o cidadão do Estado, titulares da esfera pública política e os membros da sociedade.

\subsubsection{A CAMINHO DE UMA ESFERA PÚBLICA E DA RACIONALIDADE}

Primeiramente, Habermas toma como ponto de partida a questão moral. Com as múltiplas mudanças sociais que ocorrem, passou a existir a necessidade de distinguir moral e ética. Enquanto a moral se ocuparia do exame crítico das normas (justas/injustas), a ética estaria preocupada com a elaboração e no exame crítico dos valores; a Filosofia e a Sociologia, como já mencionado, atuariam como norteadores dos atores na supracitada questão. Enquanto seres históricos e sociais, nos encontramos e nascemos num mundo de vida linguisticamente estruturado. A linguagem é um meio coletivo que permite o entendimento entre os indivíduos. Nenhum participante individual pode controlar sozinho os processos de entendimento e de autocompreensão. Os interlocutores chegam à consciência e à capacidade de tomar posição graças aos processos interativos, linguisticamente mediatizados.

Desta forma, a esfera pública funciona como integrador dos indivíduos na formação de seu exame crítico de valores éticos e morais. Ao passo que a Filosofia e a Sociologia agiriam no entendimento habermasiano nas sociedades democráticas de direito, como formuladores de princípios discursivos e racionais, exigidos para constituir uma ordem normativa. Esta ordem normativa alimenta-se, contudo, de elementos históricos e empíricos, na medida em que, por um lado, origina-se do mundo vivido do qual deduz seus princípios e, por outro, nele interfere, remodelando-o à base de seus elementos normativos jurídicos no mundo sistêmico (HABERMAS, 2003, p. 92-100).

Quando aspectos sensíveis da natureza humana, como cláusulas pétreas, estiverem em jogo, torna-se necessário um amplo debate na sociedade para renegociar o que poderia ser considerado lícito e regulamentar o que escape à esfera do individual e da moralidade interpessoal (HABERMAS, 2003, p. 92-100). Com a ética discursiva, bem como a teoria do direito discursivo, novos valores e normas exigem a abertura de debates práticos na esfera pública para institucionalizá-las e regulamentá-las, por vias discursivas, integrando os indivíduos na formação de seu exame crítico de valores éticos e morais. Todos os subsistemas seriam partilhados, independente de classe social e nível intelectual; surgiriam, portanto, mediadores de princípios discursivos e racionais, exigidos para constituir uma nova ordem normativa aceita por todos, a fim de regulamentar valores comuns a todos (HABERMAS, 2003, p. 169-211).

\subsection{HABERMAS E REPUBLICANISMO}

Diante de todo exposto, entende-se que Habermas queira perscrutar um caminho que consiga unir a moral dos direitos humanos com a soberania do povo ou a política, bem como honrar o caráter intersubjetivo dos direitos. Ou seja, busca uma formulação a partir da liberdade 
compreendida dentro do conceito de reconhecimento. Evidentemente, tudo isso prepara o caminho para ele apresentar sua teoria discursiva da democracia, que será então capaz de unir moral e direito e, também, honrar o caráter intersubjetivo da justificação dos direitos (HABERMAS, 2003, p. 169-211). Desse modo, pode-se vislumbrar que o teórico está mais próximo do republicanismo, ainda que ele diga ser um republicanismo kantiano, do que do liberalismo, pois na teoria do discurso se fundamenta a consideração de direitos e deveres em relações recíprocas de reconhecimento (HABERMAS, 2003, p. 169-211).

Todavia, o republicanismo vem ao encontro desse conceito de direito, uma vez que valoriza tanto a integridade do indivíduo e de suas liberdades subjetivas, como a integridade da sociedade na qual os particulares podem reconhecer-se, ao mesmo tempo, como indivíduos e como membros. Segundo Habermas (2003, p. 169-211), a diferença crucial entre liberalismo e republicanismo consistiria em como o papel do processo democrático é entendido. Para o liberal, o processo democrático teria a função de programar o Estado no interesse da sociedade. Já para o republicanismo, a política seria constitutiva para a socialização. A vantagem do republicanismo reside na preservação do significado democrático de uma sociedade que se organiza comunicativamente, no entanto, a sua desvantagem residiria em ser idealista demais ao fazer o processo democrático dependente de cidadãos virtuosos (HABERMAS, 2003, p. 169-211).

Habermas associa a legitimidade das leis ao processo democrático de sua gênese. O republicanismo sobrecarrega a cidadania em um sentido ético, imputando-lhe um conjunto de virtudes capaz de colocá-la em sintonia com o bem público, como formulado exemplarmente por Rousseau (RITTER, 1969, p. 270). Outrossim, é inegável que, em uma visão atual, a esfera pública de Habermas é algo mais próximo de um sistema parlamentarista e de voto distrital, contudo, o mais importante é que seja mantido um sentido jurídico que impute racionalidade ao cidadão, assim como consubstanciado na própria teoria discursiva da democracia. O modo de ler jurídico desliga o sentido do exercício dos direitos subjetivos de mandamentos morais (RITTER, 1969, p. 272), abrindo aos atores espaços de arbítrio mais amplos do que os definidos moralmente.

O conceito republicano da política não se refere aos direitos de cidadãos privados à vida, à liberdade e à propriedade, garantidos pelo Estado, porém em primeira linha, à prática de autodeterminação de cidadãos orientados pelo bem comum, que se compreendem como membros livres e iguais de uma comunidade cooperadora que a si mesma administra. Direito e lei são norteadores em relação ao contexto vital ético de uma polis na qual a virtude da participação ativa pode desenvolver-se e estabilizar-se nos negócios públicos. O homem só pode realizar o telos de sua espécie nesta prática de cidadania (RITTER, 1969, p. 272).

3.5 ESFERA PÚBLICA E SUA APLICABILIDADE NA VALIDADE DE UMA NORMA JURÍDICA

Neste ponto, será tomado como objeto de análise o complexo de opções resultantes das determinações, tanto explícitas como implícitas, das forças políticas que zelam pelo 
ordenamento legal que constitui a Constituição, apenas essa. Tomando essa Constituição como parâmetro, podemos falar do problema da validação, alteração e transformação de uma norma jurídica, na medida em que processos evolutivos e processuais permitam ou não admitir a permanência dos elementos identificadores referidos. Tecnicamente, entende-se que, no caso de normas constitucionais, nos encontramos diante da ação de um poder constituinte e, no de alterações, com poder de revisão (DINIZ, 1997, p. 55). A principal característica do poder constituinte é a desvinculação entre suas determinações e um sistema jurídico previamente vigente: ele é completamente livre na escolha dos seus objetivos. Explica-se: não acontece o mesmo com o poder de revisão, limitado, quando menos, pela obrigação de não renegar das linhas características do sistema jurídico vigente, consideradas como termo do seu uso concreto, reconhece-se que o poder de revisão está estritamente ligado à necessidade de garantir a Constituição, visando adaptá-la mediante procedimentos formalmente compatíveis com a mesma e com as novas exigências, conservando-a em seus traços essenciais e evitando recorrer a expedientes extrajurídicos. Portanto, o poder de revisão está subordinado ao poder constituinte, o único em condições de dispor e de mudar radicalmente a Constituição em sentido material (DINIZ, 1997, p. 55-80).

As modificações sancionadas por procedimentos formais constituem o núcleo dos processos de revisão que, em alguns ordenamentos, não requerem formas diversas das usadas na adoção das leis (constituições flexíveis), enquanto em outros requerem formas mais complexas, diversas das comumente usadas para a grande parte das leis; neste caso, os procedimentos, dizem-se agravados ou reforçados, dando-se maior importância às modificações da Constituição formal (caso das constituições rígidas). Por vezes, as modificações formais não são de alcance geral, mas circunscrevem-se a casos singulares; o caráter derrogatório das mesmas está implícito nas rupturas da Constituição com que são designadas. Todas as hipóteses esboçadas são expressões de modificação tendentes a perdurar (BULOS, 2001, p. 728-729).

A emenda à Constituição é o instrumento adequado para modificação ou ampliação do texto constitucional. O procedimento especial previsto no artigo 60 marca a Constituição Federal Brasileira como rígida. Desta forma, somente uma emenda poderá alterá-la; nenhuma outra espécie de lei poderá fazê-lo (BULOS, 2001, p. 728-729). Maria Helena Diniz (1997, p. 55-80) ainda anota que as ideias de supremacia da Constituição e do controle da constitucionalidade estão ligadas à de rigidez constitucional, visto que a Constituição só poderá ser alterada por meio de processo especial que ela prevê (CF, art. 60, I, II, III, $\S \S 1^{\circ}$ a $\left.5^{\circ}\right)$.

As emendas à Constituição são espécies do gênero reforma constitucional. Objetivam empreender, no texto originário da Lex Mater, mudanças localizadas, isto é, de menor abrangência. Consignam-se atos infraconstitucionais, porque não ingressam no ordenamento jurídico, nem desempenham qualquer eficácia normativa com a sua simples previsão constitucional. Apenas quando são aprovadas é que as emendas à Constituição passam a produzir efeitos concretos. Daí em diante deixam de ser atos infraconstitucionais e alcançam o posto de normas constitucionais, de igual nível e hierarquia daquelas outras elaboradas pelo poder constituinte originário. Para 
que cheguem a esse estágio, contudo, é preciso satisfazer os requisitos técnicos do procedimento legislativo especial a que estão sujeitas, conforme disposto no art. 69 da Constituição Federal (BRASIL, 2019).

Outrossim, a emenda à Constituição possui limitações circunstanciais. O texto constitucional estabelece que não poderá haver tramitação da emenda constitucional na vigência de intervenção federal (art. 34), de estado de defesa (art. 136) ou de estado de sítio (art. 137). São limitações que pretendem evitar modificações na Constituição em certas ocasiões anormais e excepcionais dos órgãos incumbidos da reforma. Trata-se de regra que visa permitir que a emenda constitucional apenas tramite em momentos de paz social. Entendeu-se, portanto, que o processo de inovação da Lex Mater deve ser feito em momento em que não haja qualquer perturbação. Trata-se de traço revelador do prestígio da Constituição Federal, que deve ser fruto de discussão serena e madura, sem ser influenciada por qualquer fator transitório (BULOS, 2001, p. 728-729).

Embora destacando-se no campo da política, algumas das transformações ocorridas na história tiveram impacto no Direito em geral, isto é, em todos os ramos e áreas do Direito. Para um panorama geral no sentido destas transformações, é preciso olhar para um grande e essencial problema: qual a melhor forma de manter e ampliar as garantias que já estão incrustadas dentro do ordenamento jurídico, frente ao processo histórico e mudança de valores pessoais. Assim como o Direito, a História pode cumprir, nos momentos de mudança, um papel restaurador, reacionário ou, ainda, um papel legitimador em um novo regime, ou, se procurarmos uma expressão mais neutra, um papel crítico. Para desempenhar este último, tem que adquirir uma atitude de suspeita permanente para com suas próprias aquisições.

A razão comunicativa não oferece normas imediatas, mas orienta a ação através de possíveis argumentações e permite a distinção entre aquilo que é digno de ser conservado e aquilo que deve ser criticado. O poder constituinte derivado, seja este o reformador, decorrente ou revisor, mesmo legitimado pela democracia, pode não considerar ou representar a racionalidade pública e incorre no risco de cometer erros que Habermas atentou, na teoria weberiana, como simplificações, ao cortar etapas e omissão de diferenciações, não diagnosticando, desta forma, corretamente a dinâmica e estrutura de uma sociedade moderna. Isso significaria que a alteração de uma norma jurídica (constitucional) carrega consigo o risco de dissenso social e desestabilização da integração. Ou seja, muitas vezes reflete-se nas normas jurídicas somente o mero poder; os meros interesses são universalizados apenas aparentemente, e, sob a capa da legitimação jurídica, é encoberta uma imposição.

\section{CONSIDERAÇÕES FINAIS}

A permanência e a naturalização da abissal desigualdade social brasileira em todas as dimensões advêm, portanto, não de um modus operandi corrupto que é associado do Estado (demonizado) e nunca do mercado (divinizado), como na visão de nosso liberalismo dominante 
que é conservador e pseudocrítico, mas, da falta de capacidade de autocrítica que perpassa toda a sociedade. Desta forma, a esfera pública não deve ser usada apenas como meio de distinção erudita, como mero adorno da inteligência. Deve ser uma arma prática para se perceber nossa própria sociedade de outro modo, mais crítico e menos autoindulgente e superficial como nos acostumamos a nos perceber.

Outrossim, a perspectiva habermasiana explode o reducionismo do positivismo jurídico, que apaga a questão da validade normativa do direito, enfocando apenas se a lei foi formalmente colocada de modo correto, isto é, coerentemente, por uma autoridade competente e que tenha força para fazê-la; conforme a prova habermasiana frente à weberiana, para que uma norma jurídica seja legítima, deve garantir para cada um as mesmas liberdades e leis morais e éticas. Isso significa que os legisladores não são autorizados a agir na posição estratégica de sujeitos privados que buscam seu próprio interesse, mas precisam assumir a posição de agentes voltados para o entendimento, isto é, de cidadãos autônomos, cujas sentenças devem poder ser aceitas por todos os participantes. Assim, no conceito de Direito fica instalado o princípio democrático de que sua legitimidade só pode ser assegurada pela aceitabilidade de suas regras por parte de todos os cidadãos livres e iguais, o que tem uma força altamente sociointegrativa.

A escola de Frankfurt e especificamente a teoria de Habermas inovam duplamente. Uma vez, pela tenacidade com que defendem suas formulações e a aproximação da política em todos os aspectos que tangenciam, direta e indiretamente, o desenvolvimento de uma sociedade democrática. A revisão dos conceitos de Habermas permite identificar um autor que analisa a democracia em patamar mundial, além das fronteiras rígidas das nações. Busca, desta forma, refletir sobre o Estado Democrático de Direito que potencialize os ideais reivindicados por Rousseau, Voltaire, Kant e Hegel, e tantos outros, desde o século XVIII: garantias fundamentadas em bases legais e morais, da vida e da dignidade da sociedade mundial. A educação, no seu sentido mais amplo de processos de formação do cidadão, deve ser o tema central de uma sociedade, a fim de criar uma cultura com um potencial para resolver problemas através de processos de aprendizagem, abrigando processos de formação social, cultural e científica, em todos os espaços. É pelo exercício da racionalidade que será possível construir conhecimento confiável e normas morais universais. O Direito, como instrumento de mediação social, necessita ser legitimado e validado por vias discursivas, pautado nas racionalidades éticas e morais, princípios renovados pela ideologia da modernidade habermasiana. O republicanismo e a democracia convencional ou radical, abordada por Habermas, insere-se, neste cenário, como meio de inserir a vontade pública, estruturada e norteada pela Sociologia e Filosofia.

A esfera pública, por sua vez, traz consigo a racionalização do indivíduo que o torna um ator efetivo dentro da pauta política e social; vislumbra-se, desta forma, a modernidade, não somente como avanços econômicos, mas como um convite para que todos participem do esforço reflexivo, assegurando uma produção teórica que resulte de processos dialógicos e da razão comunicativa, revertendo, de fato, as patologias da modernidade. 


\section{REFERÊNCIAS}

BRASIL. [Constituição (1988)]. Constituição da República Federativa do Brasil. 55. ed. São Paulo: Saraiva, 2019.

BULOS, Uadi Lammêgo. Constituição Federal anotada. 2. ed., rev. e atual., São Paulo: Saraiva, 2001.

DINIZ, Maria Helena. Norma constitucional e seus efeitos. 10. ed., São Paulo: Saraiva, 1997.

FREITAG, Barbara. Dialogando com Jürgen Habermas. 2. ed. Rio de Janeiro: Tempo Brasileiro, 2005.

HABERMAS, Jürgen. Direito e Democracia: entre facticidade e validade. Rio de Janeiro: Tempo Brasileiro, 2003. $2 \mathrm{v}$.

HABERMAS, Jürgen. Legitimationsprobleme des spãtkapitalismus. Rio de Janeiro: Tempo Brasileiro, 1980.

MCCARTHY, T. Introdução à obra The theory of communicative action, vol. 1, de J. Habermas. Boston: Beacon Press, 1984.

PINTO: José Marcelino de Rezende Pinto. A teoria da ação comunicativa de Jürgen Habermas: conceitos básicos e possibilidades de aplicação à administração escolar: Paidéia, Ribeirão Preto, n. 8-9, fev./ago. 1995.

RITTER, Joachim. Historisches wörterbuch der philosophie. Basel: Schwabe, 1969. Bd. 1-13.

BRASIL. Supremo Tribunal Federal. Adin no 829-3-DF. Relator: Min. Moreira Alves. Brasília, DF, 14 de abril de 1993. Diário da Justiça. Brasília, 16 set. 1994. 